\title{
Periodontal status and treatment needs of children from 6 to 8 years old in the Santiago Metropolitan Region of Chile
}

\section{Condição periodontal e necessidades de tratamento em crianças de 6 a 8 anos na região metropolitana de Santiago, Chile}

\begin{abstract}
Purpose: To evaluate the periodontal status and the treatment needs of Chilean schoolchildren

Methods: Prevalence study. Sample: 1,637 schoolchildren from 6 to 8 years old belonging to 26 communes of the Santiago Metropolitan Region of Chile, stratified according to socioeconomic level in accordance with the 2003 CASEN survey (National Socioeconomic Characterization Survey). Periodontal status was estimated using the Community Periodontal Index of Treatment Needs (CPITN) and following the recommendations of the WHO (World Health Organization), along with the records of the Clinical Criteria of Gingival Inflammation. Data were analyzed using a chi-square test.

Results: Gingivitis prevalence was $68.42 \%$, a result that is higher than the national prevalence $(P<0.01 ; 95 \% \mathrm{Cl}=0.66-0.70)$. The prevalence increased with age $(P<0.01)$ but was similar in both sexes $(P=0.838)$. Prevalence was relatively constant among three socioeconomic levels $(P=0.417)$. According to the CPITN, gingivitis prevalence was $29.57 \%: 27.49 \%$ consisting of children with gingival hemorrhage and $2.08 \%$ consisting of children with gingival calculus. The treatment needs of this population are that $27.49 \%$ of children require oral-hygiene instruction, and $2.08 \%$ need oral-hygiene instruction and subgingival and supragingival scaling.

Conclusion: The gingivitis prevalence found in this study was higher than the national proportion in Chile.
\end{abstract}

Key words: Prevalence of gingivitis; Community Periodontal Index of Treatment Need; epidemiology

\section{Resumo}

Objetivo: Avaliar a condição periodontal e as necessidades de tratamento de crianças escolares chilenas.

Metodologia: Estudo de prevalência. Amostra: 1637 crianças escolares de 6 a 8 anos de idade pertencentes a 26 comunidades da região metropolitana de Santiago, Chile, que foram estratificadas de acordo com o nível socioeconômico conforme o levantamento 2003 CASEN (National Socioeconomic Characterization Survey). A condição periodontal foi estimada usando o índice Community Periodontal Index of Treatment Needs (CPITN) e seguindo as recomendações da Organização Mundial de Saúde (OMS), juntamente com os registros de critérios clínicos de inflamação gengival. Os dados foram analisados por testes qui-quadrado.

Resultados: A prevalência de gengivite foi de $68,42 \%$, resultado que é maior que a prevalência nacional do Chile $(P<0,01 ; 95 \% \mathrm{Cl}=0,66-0,70)$. A prevalência aumentou com a idade $(P<0,01)$, mas foi similar em ambos os sexos $(P=0,838)$. A prevalência foi relativamente constante entre os três níveis socioeconômicos $(P=0,417)$. Para CPITN, a prevalência de gengivite foi de 29,57\%: 27,49\% com sangramento gengival e 2,08\% s com cálculo gengival. As necessidades de tratamento desta população foram de $27,49 \%$ de crianças que necessitavam de instrução de higiene bucal e 2,08\% que necessitavam de instrução de higiene bucal e raspagem supra e subgengival.

Conclusão: A prevalência de gengivite neste estudo foi maior que a proporção nacional no Chile.

Palavras-chave: Prevalência de gengivite; epidemiologia

\section{Francisca Varas a \\ Gisela Zillmann a \\ Andrea Muñoz a \\ José Hassi a \\ Ismael Yévenes a \\ Sonia Echeverría a \\ Paula Maass a \\ Renata Quintana a}

- Dental School, University of Chile, Santiago, Chile

\author{
Correspondence: \\ Ismael Yévenes L \\ Department of Chemistry, Dental School \\ University of Chile \\ Sergio Livingstone (ex-Olivos) 943, Independencia \\ Santiago, Chile \\ E-mail: iyevenes@odontologia.uchile.cl
}

Received: December 7, 2010

Accepted: February 14, 2011

Conflict of Interest Statement: The authors state that there are no financial and personal conflicts of interest that could have inappropriately influenced their work.

Copyright: (C) 2011 Varas et al.; licensee EDIPUCRS. This is an Open Access article distributed under the terms of the Creative Commons AttributionNoncommercial-No Derivative Works 3.0 Unported License. 


\section{Introduction}

Periodontal disease is one of the most prevalent pathologies of the oral cavity, and it is found in all age groups $(1,2)$. There is a lot of important information about the diagnosis and treatment of periodontal diseases in adults, but there is relatively little information about the diagnosis, prevention and treatment of periodontal diseases in children (3).

The predominant form of periodontal disease in children and adolescents is gingivitis (1-8). Gingivitis is the most important oral disease and the most prevalent among the pediatric population, exceeded only by dental caries $(1,6,7)$. Gingivitis of varying severity is almost universally present in children and adolescents $(2,3,5-7)$. Periodontitis is less frequent during childhood $(3,6)$.

Epidemiological studies have shown a broad variation in gingivitis prevalence rates in children of different populations, varying from $35 \%$ to $100 \%$ (2). There are few national epidemiological studies in Chile on the prevalence of periodontal diseases in children and adolescents $(7,9,10)$.

In accordance with the above-mentioned observations, the purposes of this study were to determine the prevalence of gingivitis in a sample of schoolchildren from 6 to 8 years old in the Santiago Metropolitan Region of Chile and to associate the prevalence with age, sex and socioeconomiclevel variables, aiming to contrast the results with earlier national data in order to provide the background for prevention and treatment strategies that can been developed over this time.

\section{Methods}

Type of study

This study was a cross-sectional, epidemiological, twophased descriptive study of prevalence, with a probabilistic design and stratified by socioeconomic level.

\section{Sample}

A total of 1,637 schoolchildren from 6 to 8 years old, without systemic disease, were randomly selected from 26 communes of the Santiago Metropolitan Region and were stratified according to socioeconomic level, in accordance with the Commune Poverty Ranking elaborated by the 2003 CASEN survey (11).

\section{Clinical evaluation}

Clinical evaluation through a pilot study was carried out before the research began, with the aim of testing the working methodology in the field. The pilot sample was composed of 45 children, representative of all schooling and socioeconomic levels considered in the study. The clinical evaluation was performed by four expertcalibrated examiners (Kappa test $=93 \%$ ). Samples were collected after each participant's informed consent was obtained in writing. A WHO periodontal probe and mirror were used, and data were recorded on a simplified WHO card.
Gingivitis diagnosis

The Community Periodontal Index of Treatment Needs (CPITN) was used to establish a gingivitis diagnosis, according to the methodology for epidemiological studies described by WHO $(12,13)$. In patients younger than 20 years old, the evaluation was performed on 6 index teeth $(16,11,26$, 36, 31 and 46) and codes 3 and 4 were not considered to avoid the recording of false sacs associated with tooth eruption. Maximum punctuation for the whole mouth was used as a treatment recommendation (13). Also, code 1 was used if the presence of at least 2 Clinical Criteria of Gingival Inflammation were observed when conducting the evaluation $(14,15)$.

The gingivitis diagnosis was determined according to the CPITN records of the index teeth (codes 1 or 2) (16), along with the presence of at least two sites meeting Clinical Criteria of Gingival Inflammation criteria being observed during evaluation $(14,15)$.

\section{Statistical Analysis}

The statistical analysis of the data obtained was carried out using the Stata computer program, version 8.1 (StataCorp LP, Texas, USA). A chi-square test was used to analyze the differences among the variables in study, a difference in proportions test was used to compare the prevalence rates. A significance level of 0.05 was adopted for all tests.

\section{Results}

\section{Demographic Characteristics of the Sample}

Of the sample from the Metropolitan Region of 1,637 schoolchildren, 566 children $(34.57 \%)$ were 6 years old, 558 children $(34.09 \%)$ were 7 years old, and 513 children (31.34\%) were 8 years old. Regarding the distribution by sex, 804 (49.11\%) were boys, and 833 (50.89\%) were girls. Regarding socioeconomic level, the sample distribution included 278 children (16.98\%) from a high socioeconomic status, 547 children $(33.42 \%)$ from a medium socioeconomic status, and $812(49.60 \%)$ from a low socioeconomic status.

\section{Prevalence of Gingivitis}

Gingivitis prevalence was determined according to the CPITN and based on the presence of Clinical Criteria of Gingival Inflammation. Thus, from a total sample of 1637 children, it was determined that 517 children $(31.58 \%)$ were periodontally healthy, while 1120 children $(68.42 \%)$ presented with gingivitis (Table 1).

Table 1. Gingivitis prevalence in the study sample of Chilean schoolchildren.

\begin{tabular}{lcc}
\hline \multicolumn{1}{c}{ Gingivitis } & $\mathrm{N}$ & $\%$ \\
\hline Healthy & 517 & 31.58 \\
III & 1,120 & 68.42 \\
Total & 1,637 & 100.00 \\
\hline
\end{tabular}

Gingivitis diagnosis was defined according to the CPITN records in the index teeth (codes 1 or 2) (14), along with the presence of at least 2 sites meeting Clinical Criteria of Gingival Inflammation criteria observed when evaluating $(15,16)$. 
It was observed that the prevalence of gingivitis increased with age. A total of $55.48 \%(n=314)$ of the 6-yearold children presented with gingivitis, while the prevalence rose to $76.16 \%(\mathrm{n}=425)$ in 7 -year-old children and $74.27 \%$ $(\mathrm{n}=381)$ in 8 -year-old children. There was a significant statistical difference $(P<0.01$, chi-square test $)$ between 6 -year-old children and children who were 7 and 8 years old (Table 2).

Regarding sex, gingivitis was present in $68.66 \%(\mathrm{n}=552)$ of the boys and in $68.19 \%(\mathrm{n}=568)$ of the girls, with no significant statistical difference in gingivitis prevalence in relation to sex $(P=0.838$, chi-square test) (Table 3$)$.

With regard to socioeconomic level, gingivitis prevalence remained relatively constant among the three levels, being present in $65.11 \%(\mathrm{n}=181)$ of the children of high socioeconomic status, in $69.29 \%(n=379)$ of the children of medium socioeconomic status, and in $68.97 \%(n=560)$ of the children of low socioeconomic status. No significant statistical difference in gingivitis prevalence was found in relation to socioeconomic level ( $P=0.417$, Chi-square test $)$ (Table 4).

When comparing the gingivitis prevalence of $68.42 \%$ measured in this study with the previously measured prevalence of $37.7 \%$ at a national level (Mella, 1992) (17), a significant statistical difference $(P<0.01 ; 95 \% \mathrm{IC}=0.66$ 0.70 , difference in proportions test) was observed, and the value obtained in the current study greatly exceeded the reference value.

Community Periodontal Index of

Treatment Needs (CPITN)

The CPITN was used as an indicator of gingival status, and only codes 0,1 and 2 were recorded, in accordance with what is described in the Methods section. In accordance with this index, of the 1,637 children examined, $70.43 \%$ $(n=1,153)$ were periodontally healthy, $27.49 \%(n=450)$ presented with gingival hemorrhage, and $2.08 \%(\mathrm{n}=34)$ presented with gingival calculus (Table 5).

Table 2. Gingivitis prevalence by age.

\begin{tabular}{|c|c|c|c|c|c|c|c|c|}
\hline \multirow{3}{*}{ Gingivitis } & \multicolumn{6}{|c|}{ Age (years) } & \multicolumn{2}{|c|}{ Total } \\
\hline & \multicolumn{2}{|c|}{6} & \multicolumn{2}{|c|}{7} & \multicolumn{2}{|c|}{8} & \multirow{2}{*}{$\mathrm{N}$} & \multirow{2}{*}{$\%$} \\
\hline & $\mathrm{n}$ & $\%$ & $n$ & $\%$ & $\mathrm{n}$ & $\%$ & & \\
\hline Healthy & 252 & 44.52 & 133 & 23.84 & 132 & 25.73 & 517 & 31.58 \\
\hline III & 314 & 55.48 & 425 & 76.16 & 381 & 74.27 & 1,120 & 68.42 \\
\hline Total & 566 & 100.00 & 558 & 100.00 & 513 & 100.00 & 1,637 & 100.00 \\
\hline
\end{tabular}

With significant statistical difference $(P=0.0001$, chi-square test) between children 6 years old and children 7 and 8 years old.

Table 3. Gingivitis prevalence by sex.

\begin{tabular}{lrrrrrr}
\hline \multirow{2}{*}{ Gingivitis } & \multicolumn{4}{c}{ Sex } & \multicolumn{2}{c}{ Total } \\
\cline { 2 - 5 } & \multicolumn{2}{c}{ Male } & \multicolumn{1}{c}{ Female } & \multirow{2}{*}{$\mathbf{n}$} & \multirow{2}{*}{$\%$} \\
\cline { 2 - 5 } & 252 & 31.34 & 265 & 31.81 & 517 & 31.58 \\
Healthy & 552 & 68.66 & 568 & 68.19 & 1,120 & 68.42 \\
III & 804 & 100.00 & 833 & 100.00 & 1,637 & 100.00 \\
\hline
\end{tabular}

No significant statistical difference between sexes $(P=0.838$, chi-square test $)$

Table 4. Gingivitis prevalence by socioeconomic level.

\begin{tabular}{|c|c|c|c|c|c|c|c|c|}
\hline \multirow{3}{*}{ Gingivitis } & \multicolumn{6}{|c|}{ Socioeconomic level } & \multicolumn{2}{|c|}{ Total } \\
\hline & \multicolumn{2}{|c|}{ High } & \multicolumn{2}{|c|}{ Medium } & \multicolumn{2}{|c|}{ Low } & \multirow{2}{*}{$N$} & \multirow{2}{*}{$\%$} \\
\hline & $\mathrm{n}$ & $\%$ & $\mathrm{n}$ & $\%$ & $\mathrm{n}$ & $\%$ & & \\
\hline Healthy & 97 & 34.89 & 168 & 30.71 & 252 & 31.03 & 517 & 31.58 \\
\hline III & 181 & 65.11 & 379 & 69.29 & 560 & 68.97 & 1,120 & 68.42 \\
\hline Total & 278 & 100.00 & 547 & 100.00 & 812 & 100.00 & 1,637 & 100.00 \\
\hline
\end{tabular}

No significant statistical difference among the three socioeconomic levels $(P=0.417$, chi-square test)

Table 5. Gingivitis prevalence according to the Community Periodontal Index of Treatment Needs.

\begin{tabular}{|c|c|c|}
\hline Mouth maximum & $\mathrm{N}$ & $\%$ \\
\hline Healthy $(0)$ & 1,153 & 70.43 \\
\hline Hemorrhage (1) & 450 & 27.49 \\
\hline Calculus (2) & 34 & 2.08 \\
\hline Total & 1,637 & 100.00 \\
\hline
\end{tabular}


Analyzing in detail the values obtained using the CPITN according to sextant, similar percentages were observed in all the sextants in healthy children. Gingival hemorrhage was present to a greater extent in the first and third sextants (teeth 16 and 26), at rates of $16.74 \%$ and $13.01 \%$, respectively, when compared with the other sextants. The incidence of gingival calculus observed was low; the highest rate was found in the fifth sextant (tooth 31 ) at $1.34 \%$.

In accordance with the values obtained from the CPITN, the treatment needs for this population can be estimated according to the suggestions given by WHO (13). Thus, the healthy children (0 CPITN) $(70.43 \%)$ obviously do not need periodontal treatment (Treatment I). Children presenting with gingival hemorrhage (1 CPITN) $(27.49 \%)$ require oral-hygiene instruction (Treatment II). Finally, children presenting with gingival calculus (2 CPITN) $(2.08 \%)$ not only require oral-hygiene instruction, but also supragingival and subgingival scaling (Treatment III) (Table 6).

Table 6. Periodontal treatment needs in accordance with the CPITN.

\begin{tabular}{lcrr}
\hline Mouth maximum & Treatment need & \multicolumn{1}{c}{ N } & \multicolumn{1}{c}{$\%$} \\
\hline Healthy (0) & I & 1,153 & 70.43 \\
Hemorrhage (1) & II & 450 & 27.49 \\
Calculus (2) & III & 34 & 2.08 \\
Total & & 1,637 & 100.00 \\
\hline
\end{tabular}

(0) Healthy; (1) Hemorrhage when teeth were probed, observed directly or using an oral mirror; (2) Supragingival or subgingival calculus, observed when teeth were probed. It was visible across the whole black band of the probe. Treatment need: (I) No need for treatment; (II) Need for oral-hygiene instruction; (III) Need for oralhygiene instruction + supragingival and subgingival scaling + root planning (13).

\section{Discussion}

Gingivitis is the most important disease and is the most prevalent condition in the child population after dental caries $(1,6,7)$. The purpose of this study was to determine the prevalence of gingivitis in a sample of Chilean schoolchildren, with the goal of contrasting the results with the previous data. Comparing our $68.42 \%$ with the 37.7\% rate found in Mella's study in 1992 (17), a significant statistical difference was observed. The value obtained greatly exceeded the previous study, being almost double. This difference in prevalence rates may be due to the fact that the current study covered a representative sample of children from only 6 to 8 years old from the Santiago Metropolitan Region, while the referenced study covered a sample of children from 6 to 12 years old and on a national level. However, the prevalence rate obtained in the current study is similar to that determined by Sayegh et al. (2005) in Jordanian children of 4 to 5 years of age (66\%) (18) and to that determined by Feldens et al. (2006) in Brazilian children of 3 to 5 years of age (77\%) (2). However, these values are much greater than the $13 \%$ prevalence found by Cosic et al. (2005) in 6-to-12-year-old schoolchildren in the Netherlands (19).

In Chile, there are few national epidemiological studies and little accurate data about the prevalence of periodontal diseases in children $(7,9,10)$. The extant studies report prevalences ranging from approximately $40 \%$ to $98 \%(1,9)$. The $68.42 \%$ prevalence observed in this study falls within that range. Fernández (1987) also observed a high rate of gingivitis prevalence, i.e., $96 \%$, but in older students between the ages of 15 and 18 years old (20). Similarly, Núñez et al. (2004) observed a gingivitis prevalence of $73 \%$ in children 12 years old from the Metropolitan Region (21). Palma (2007) reported a prevalence of $60 \%$ of children studied having mild gingivitis and $40 \%$ having moderate gingivitis in a study of schoolchildren from the Metropolitan Region (7). Soto et al. (2007) found a gingivitis prevalence of $67 \%$ in children 12 years old (22).

It was observed that the prevalence of gingivitis increased with age. This increase with age may be due to exfoliation and tooth-eruption processes, which contribute to a higher accumulation of bacterial plaque. In children 10 years old, Hugoson at al. found that gingivitis was more prevalent in regions with teeth in eruption (23).

Todd and Dodd (1985) also found that the prevalence of gingivitis increases with age, being present in $18 \%$ of 5 -year-old children, in $40 \%$ of 7 -year-old children, in 54\% of 11 -year-old children, and in 54\% of 15 -year-old adolescents (24). Similarly, Massler et al. and Parfitt observed that the prevalence and extension of gingivitis rose with age, beginning with the temporal dentition and reaching its peak during puberty $(25,6)$.

Regarding sex, there was no significant statistical difference $(P=0.838)$ between the sexes; therefore, sex is not a gingivitis risk predictor in this population. Núñez et al. (2004) reported similar values of gingivitis prevalence in children 12 years old, finding rates of $35.6 \%$ in boys and $37.4 \%$ in girls (21). Also, in Palma's study (2007) there was no significant statistical difference with relation to sex (7). Feldens et al. (2006) observed the same trend (2).

Most of the studies have demonstrated a significantly lower prevalence of periodontal diseases in women than in men from young ages (1). Soto et al. (2007) reported a significant statistical difference in gingivitis prevalence with relation to sex in children 12 years old, with the prevalence being higher in males (22). Fernández (1987) found this same phenomenon among students from 15 to 18 years old (20).

Regarding socioeconomic level, the prevalence of gingivitis remained relatively constant among the three socioeconomic levels. The same result was observed in Mella's study in 1992 (17), unlike the studies by Nuñez et al. (2004) (21) and Feldens et al. (2006) (2). Nevertheless, other epidemiological studies suggest that periodontal disease is more prevalent and more severe in populations of low socioeconomic status and educational level (1). In the study by Soto et al. (2007) in 12-year-old children, a significant statistical difference was observed in gingivitis prevalence with relation to socioeconomic level, with gingivitis being more common in the lower income levels (22).

Gingivitis diagnosis was performed using the Community Periodontal Index of Treatment Needs, along with the observation of criteria of the Clinical Criteria of Gingival 
Inflammation. Almans et al. (1991) compared the CPITN with other periodontal indices, such as the Plaque Index (PI), the Gingival Index (GI), the Papillary Bleeding Index (PBI), and the Probing Depth (PD). They found no relationship between the CPITN and the PI or the GI, but they did find a tendency for the PBI and the PD to be related. The authors concluded that the CPITN can be used as a general indicator of periodontal conditions, but other indices are required to evaluate periodontal status more precisely (27). Cutress et al. (1986) compared the CPITN with the Periodontal Index (PI). They found that the CPITN was more sensitive to the identification of existing periodontal conditions and that the treatment needs were comparable to those found with the PI due to the clinical criteria and the periodontal probe used. The authors concluded that, although their original purposes differed, the CPITN is preferable to the PI as an epidemiological detection procedure to evaluate periodontal treatment needs (28).

In the current study, the CPITN indicated that gingivitis prevalence was $29.57 \%$, with $27.49 \%$ of children having gingival hemorrhage and $2.08 \%$ of children having gingival calculus. These values are similar in proportion to the ones found by Gómez et al. (1998), in their study of the periodontal status in 7-year-olds students, used the CPITN and reported a gingivitis prevalence of $44.3 \%$, with $41.9 \%$ of children having gingival hemorrhage and $2.42 \%$ of children having calculus; no differences were found based on sex (29). Similarly, Soto et al. (2007) also used the CPITN to determine the prevalence of gingivitis in Chilean children who were 12 years old. They reported a gingivitis prevalence of $67 \%$, with $38.8 \%$ of children having gingival hemorrhage and $28.1 \%$ of children having gingival calculus (22). Núñez et al. (2004), using the CPITN, found $9.6 \%$ of his study subjects having gingival hemorrhage and $0.8 \%$ having calculus in 12-year-old children in the Metropolitan Region. Teeth 16 and 26 were the most affected by hemorrhage, and tooth
31 was the most affected by calculus (21). Regarding the prevalence of gingival calculus, these data agree with those observed by O'Brien (1993) in the United Kingdom, where the proportion of children with calculus gradually increased from $5 \%$ in 5 -year-old children to $32 \%$ by the age of 15 .

When analyzing the values obtained using the CPITN by sextants, similar percentages were observed in healthy children in all the sextants. Gingival hemorrhage was present in greater numbers in the first and third sextants (teeth 16 and 26) in comparison to the other sextants. The values of gingival calculus obtained were low; the highest percentage was found in the fifth sextant (tooth 31). These results coincide with those observed by Núñez et al. (2004) in children 12 years old (21). Feldens et al. (2006) also observed that, in children from 3 to 5 years old, gingival bleeding was more prevalent in posterior teeth (2). This distribution is likely to be due to the lesser ability to carry out a good oral hygiene in this region and the proximity of the salivary glands to those areas of the oral cavity.

Given the large amount of damage observed in this population across different socioeconomic levels and in both sexes and given the high rates of gingivitis prevalence reported by other studies in Chile, reinforcement of the existing promotional and preventive actions is recommended, emphasizing the responsibility of both the health professional and the patient, at both an individual level and at a community level, and in a coordinated manner between the health services and the educational institutions.

\section{Conclusions}

Because the gingivitis prevalence found in this study sample of schoolchildren was higher than the national proportion, reinforcement is suggested of the existing promotional and preventive actions related to periodontal diseases in Chile.
References
1. Chile. Ministerio de Salud. Regulation for the prevention of gingival and periodontal diseases. Human Health Division. Department of Odontology. Chilean Health Ministry; 1998.

2. Feldens EG, Feldens CA, Kramer PF, Ferreira SH. Distribution of plaque and gingivitis and associated factors in 3- to 5-year-old Brazilian children. J Dent Child 2006;23:4-10.

3. Escobar F. Pediatric Odontology. 2nd ed. Caracas (Venezuela): Actualidades MédicoOdontológicas Latinoamérica; 2004.

4. Bimstein E. Seven-year follow-up of 10 children with periodontitis. Pediatr Dent 2003 25:389-96.

5. Pinkham JR. Odontología Pediátrica. $3^{\text {rd }}$ ed. Mexico City: McGraw-Hill Interamericana Editores; 2001.

6. American Academy of Periodontology. Guideline on periodontal diseases in children and adolescents. J Periodontol 1996;67:57-62.

7. Palma P, Gajardo M. Periodontal pathogens in children from 8 to 11 years old in two schools of the Metropolitan Region. Association with gingivitis. Rev Soc Chil Odontopediatría 2008;23:40

8. Mariotti A. Dental plaque-induced gingival diseases. Ann Periodontol 1999;4:7-17.

9. Chile. Ministerio de Salud. Epidemiological profile of the oral health. Department of Odontology. Chilean Health Ministry; 1999. 
10. Chile. Ministerio de Salud. Comprehensive oral health clinic guide for children of 6 years old. Chilean Health Ministry; 2005.

11. Chile. Ministerio de Planificación. 2003 National Socio-Economic Characterization Survey (CASEN). Chilean Planning and Cooperation Ministry; 2004.

12. World Health Organization. Oral Health Surveys. Basic Methods. $4^{\text {th }}$ ed. Geneva: WHO; 1997.

13. Cutress TW, Ainamo J, Sardo-Infirri J. The Community Periodontal Index of Treatment Needs (CPITN) procedure for population groups and individuals. Int Dent J 1987;37:222-33.

14. Bassani DG, da Silva CM, Oppermann RV. Validity of the Community Periodontal Index of Treatment Needs' (CPITN) for population periodontitis screening. Cad Saúde Pública 2006;22:277-83.

15. Carranza FA, Newman MG. Clinical Periodontics. $8^{\text {th }}$ ed. Mexico: McGraw-Hill Interamericana Editores; 1998.

16. Armitage GC. Development of a classification system for periodontal diseases and conditions. Ann Periodontol 1999;4:1-6.

17. Mella S. Oral morbidity and treatment needs in children of 6 and 12 years old in Chile [thesis]. Santiago (Chile): Dental School, University of Chile; 1992.

18. Sayegh A, Dini EL, Holt RD, Bedi R. Oral health, sociodemographic factors, dietary and oral hygiene practices in Jordanian children. J Dent 2005;33:379-88.

19. Cosic K, Bos CA, van Jaarsveld CH, van der Schans CP. Caries prevalence and oral health among schoolchildren. Ned Tijdschr Tandheelkd 2005;1 12:358-62.

20. Fernández $\mathrm{O}$. Study of oral health in elementary and high school students of the metropolitan region and of the human resources needed for their treatment [thesis]. Santiago (Chile): University of Chile; 1987.

21. Núñez C, Zillmann G, Muñoz A, Echeverría S, Hassi J. Periodontal status in children of 12 years old. Metropolitan Region. 2004. Rev Soc Chil Odontopediatría 2006;21:43.

22. Soto L, Tapia R, Jara G, Rodríguez G, Urbina T, Martínez B, Aranda W. National diagnosis of the 12 years old adolescents' oral health and evaluation of the complying degree of the oral health sanitary objectives for 2000-2010. Faculty of Dentistry. Technical Documents Series. Santiago (Chile): Ediciones Universidad Mayor; 2007.

23. Hugoson A, Koch G, Rylander H. Prevalence and distribution of gingivitis-periodontitis in children and adolescents. Epidemiological data as a base for risk group selection. Swed Dent J 1981;5:91-103.

24. Todd JE, Dodd T. Children's dental health in the United Kingdom - 1983. London (UK): Her Majesty's Stationery Office; 1985.

25. Massler M, Schour I, Choppa B. Ocurrence of gingivitis in suburban Chicago school children. J Periodontol 1950;21:146-64.

26. Parfitt GJ. A five-year longitudinal study of the gingival conditions of a group of children in England. J Periodontol 1957;28:26-32.

27. Almas K, Bulman JS, Newman HN. Assessment of periodontal status with CPITN and conventional periodontal indices. J Clin Periodontol 1991;18:654-9.

28. Cutress TW, Hunter PB, Hoskins DI. Comparison of the Periodontal Index (PI) and Community Periodontal Index of Treatment Needs (CPITN). Community Dent Oral Epidemiol 1986;14:39-42.

29. Gómez G, Doreste JL, Sierra A, Serra LI. Periodontal status of schoolchildren of 7 and 12 years old in the Canaries. RCOE 1999;3(8).

30. O'Brien M. Children's dental health in the United Kingdom - 1993. London (UK): HMSO; 1994. 